\title{
Active Learning Strategies for Complementing the Lecture Teaching Methods in Large Classes in Higher Education
}

\author{
Jeffrey A. Mangram | Marcelle Haddix | Moses K. Ochanji | Joanna Masingila \\ Massification in higher education in Sub-Saharan Africa is an ongoing reality that poses particular challenges and opportu- \\ nities for these nations (Mohamedbhai, 2008). Like Scott (1995), we use the term massification to refer to the rapid increase of \\ students attending higher education institutions in the latter part of the 20th century and into the 21st century. We contend that \\ even in large lecture hall situations, active teaching strategies can be employed to check for understanding, to engage more
} students in grappling with the content in deeper and more complex ways, and to model for prospective teachers on how to use these techniques to engage their future students in large classroom contexts.

In this expository paper, we outline the professional development training we conducted with Kenyatta University teacher educators. We focused on teaching and modeling twelve active learning strategies that they could use in their classes, which are held in lecture halls with as many as 500 students in a class, and were useful active learning strategies regardless of the number of students in the class. By using the aforementioned active learning strategies, we believe the lecture method can be transformed into a tool that promotes active rather than passive learning. Massification does not have to mean a lower-quality learning experience despite large class sizes. Indeed, we argue that massification means a different learning experience for lecturers and students.

Massification in higher education in Sub-Saharan Africa is an ongoing reality that poses particular challenges and opportunities for these African nations (Mohamedbhai, 2008). Like Scott (1995), we use the term massification to refer to the rapid increase of students attending higher education institutions in the latter part of the 20th century and into the 21st century. According to Mohamedbhai (2008), funding, quality of education, relevance of education, teaching, learning, and research, infrastructure, and quality of student life are all issues with which higher education institutions are grappling. For example, regarding teaching, learning and research, the United Nations Organization for Education, Science and Culture (UNESCO) reported that instructors' teaching methods have not evolved to effectively engage the overcrowded classroom (UNESCO, 1997); instructors lecture and assess their students on rote memorization (Biggs, 1999). Faced with large class sizes that range between 400-1,000 students (Mulryan-Kyne, 2010), instructors are not only becoming discouraged due to lack of resources and the inordinate amount of time it takes to grade student assignments, but also because their ability to conduct research is short-circuited.

Although massification in higher education presents many challenges, it also presents opportunities. One of the factors contributing to massification in Sub-Saharan Africa is that governments are 
investing in their youth and mortality rates are lower with improved economic and health prospects. Governments are mandating compulsory free primary and secondary education, thus more students are attending and completing secondary education. For instance, 31 million African students enrolled in secondary education from 1999-2004, an increase of 43\% (UNESCO, 2007). As Bloom (2005) suggested, governments understand the direct link between higher education and healthy lifestyles, economic development, and personal empowerment. Hence, in some instances, subsidized by the government, many students seek higher education to build on their human capital, which will in turn benefit the society. UNESCO (1999) asserted that large shifts of student enrollment to higher education are positive, demonstrating democratization of access in which more than the society's elite populations are being educated. What, then, are the implications for educators in higher education institutions, particularly teacher educators, who may have 400 to 1,000 students in their lecture halls? Does massification mean the end of quality education?

To address massification, many higher education institutions in Sub-Saharan African nations are transforming their finance and governing models, enacting evaluation and accreditation systems, rewriting their curricula, enhancing their technological systems, and redefining quality assurance (Mohamedbhai, 2008). With regards to massification and quality assurance, the central question is: Do more students in the lecture hall mean a lower quality learning experience or do more students in the lecture hall simply mean a different learning experience (Swain, 1999)? Specifically, in schools of education where teacher preparatory methods courses are being taught, can the quality of the educational experience be enhanced through the very pedagogical methods employed by the instructor?

We contend that even in large lecture hall situations, active teaching strategies can be employed to check for understanding, to engage more students in grappling with the content in deeper and more complex ways, and to model for prospective teachers, techniques to engage their future students in large classroom contexts. In this expository paper, we outline the professional development training we conducted with Kenyatta University teacher educators; we focused on teaching and modeling twelve active learning strategies that they could use in their classes regardless of the number of students in a class. In the following sections, we discuss the rationale and context of this work, as well as define and explain the strategies we taught the teacher educators and our reasoning behind choosing each strategy.

\section{RATIONALE}

In order for students to develop deeper, clearer meaning and understanding of what they are taught, they need to be actively involved in the learning process. Active participation of the student in the learning process is of paramount importance in the formulation of meaningful comprehension and the understanding of the content being learned. Active learning is a key element of constructivist learning theory. The theory suggests that humans construct knowledge and meaning from their experiences (Chrenka, 2001). In a constructivist classroom, the students are the focus and the teacher is a facilitator who asks good questions that guide students to construct meaning. As a working definition, Bonwell and Eison (1991) suggested, "active learning be defined as anything that involves students in doing things and thinking about what they are doing" (p. 2). In other words, students are engaged and at the center of the learning process.

Active learning is often identified by specific pedagogical learning activities. Many techniques can be used to get the students involved, including "experiential learning, cooperative learning, problem-solving exercises, writing tasks, speaking activities, class discussion, case-study methods, simulations, role-playing, peer teaching, fieldwork, independent study, library assignments, computer-aided instruction, and homework" (Houston, 1995, p. 2). The method of active learning a teacher chooses will depend upon the situation (i.e., what is being taught to what level of student). For many teachers, these strategies are a common menu on their professional development workshops and are anything but new. However, implementing such strategies in class sizes of about 400 students can pose challenges that have not been previously addressed in many professional development workshops.

One of the results of the massification in higher education is large class size. Given the large class sizes in many Sub-Saharan universities, lecturing has remained the most predominant format of 
content delivery. This approach to teaching fails to provide the necessary engagement typical of active learning. At the same time, many instructors are short of strategies to engage large number students in active learning. Disrupting lecture-only teaching in large classes was one of the goals of this professional development on actively engaging students in learning in large classes.

\section{CONTEXT}

Kenyatta University and Syracuse University have had an institutional linkage since 2000, which grew out of co-author Joanna Masingila's Fulbright Scholar experience at Kenyatta University in 1998. Colleagues at the two universities have worked together on co-sponsored international conferences, and professional development workshops for instructors in Kenya. Additionally, 26 students from Kenyatta University have come to Syracuse University for graduate studies.

Kenyatta University and Syracuse University were awarded a grant funded by the United States Agency for International Development in 2011 through the Africa - U.S. Higher Education Initiative. The focus of the grant project was on building capacity in teacher education. The project activities included scholar exchanges, collaborative research projects, program and curriculum review and revision based on data from recent graduates, collaborating with educational stakeholders to improve teacher preparation and development, and professional development for teacher educators at Kenyatta University focused on teaching large classes, integrating technology, and supporting all learners.

In this paper, we discuss a three-day professional development workshop that engaged teacher educators from Kenyatta University in exploring and using active learning strategies with a particular focus on implementing them in large classes. Faculty members from Syracuse University and one of its partner schools led the workshop.

Education courses at Kenyatta University often enroll between 250-450 students for subject methods courses and up to 1,000 students for introductory courses. Class sessions are held in large lecture halls and meet for three hours per week. During prior professional development workshops, the Kenyatta University teacher educators talked about their desire to more actively engage their students in learning, and to model and teach strategies that their students (who are prospective teachers) would be able to use in their future secondary school teaching practice. While the 20 workshop participants did not constitute a "large class" compared to the size of the classes that these teacher educators typically teach, throughout the workshop we asked the teacher educators to think about the use of these strategies while considering what they know about teaching large classes. By keeping this focus during our discussions about the strategies, the teacher educators were able to draw on their teaching experiences in large classes to think constructively about applying them in large lecture classes.

In planning this professional development workshop, we decided to introduce four active learning strategies each of the three days, engage the teacher educators with the strategy, and then have them work on making concrete plans for using these strategies in their teaching. The four professors, Drs. Jeffery Mangram, Marcelle Haddix, Moses Ochanji and Joanna Masingila, each chose strategies that they were familiar with and that represented pedagogies that have the potential to actively engage students, even in large classes.

For the first day, we chose to engage the teacher educators with the strategies of Opening Question/Reflection, Cold Call: Not Opt Out/Stretch It, HRASE Questioning, and Two-minute Paper. We chose Focused Listing, Note Check, Write-PairShare or Think-Pair-Share, and Flipped Classroom for the second day. For the third day, we selected Scenarios/Case Studies, Reciprocal Questioning, Visual Literacy, and Technology-based Check In.

In the next section of this paper, each of the authors discusses the strategies that he or she chose to present and the rationale for these choices. We have grouped these strategies into three categories - Questioning and Reflection Strategies, Writing Strategies, and Technology-supported Strategies and discuss the strategies using first-person narratives.

\section{QUESTIONING AND REFLECTION STRATEGIES}

Masingila's narrative. I chose Opening Question/Reflection for one of the strategies I presented. In this strategy, the instructor uses a question to begin the lesson. The instructor presents the question/reflection on a PowerPoint slide or through another visual means, gives students a moment to 
think about their response, and then asks a few students for their responses. This strategy is helpful in focusing students' attention on the lesson's topic and provides the instructor with useful feedback on what the students know and do not know about the topic. During the workshop, I engaged the teacher educators with this opening question: "Take a moment to reflect on your experience having students contribute their ideas in class. Come up with a positive and a negative example."

This strategy can take as little as three to five minutes to implement and has the potential to get students thinking about a topic related to the day's lesson. I chose this strategy because it is one that can be used in a lecture hall with large classes, it is fairly easy to implement even for those instructors who typically use only a lecture approach, and it supports students' learning by focusing them on the topic for the lesson.

Mangram's narrative. The first active learning strategy that I chose to present to the instructors was Cold Call. I chose this strategy because instructors of large classes are often reluctant to actively engage their students in such a setting (Biggs, 1999). Cold Call refers to the teaching strategy in which the instructor randomly calls on students to answer questions or make comments, even though a student may not have their hand raised (Lemov, 2010). This technique is not to be used as a disciplining technique. Instead, the technique implicitly communicates four key expectations: (1) students should pay attention; (2) students should participate; (3) instructors will call on other students beside those who raise their hands; and (4) instructors will check for understanding as the lesson or lecture is being taught.

As I explained the technique during the workshop, I randomly called on instructors, asking "What did you hear me say?" or "Could you explain that concept in your own words?" Immediately, the instructors were taken aback because they felt that I was putting them on the spot. Eventually, they understood that Cold Call is designed to send an implicit expectation - everyone is expected to participate and actively engage with the lesson content.

Some instructors may think this technique is problematic because students may simply say, "I do not know." To respond to such comments, I employed the complementary learning strategy of No Opt Out with Cold Call (Lemov, 2010). Simply, No
Opt Out allows instructors to call on another student to answer the question the previous student could not answer, but then go back to the first student and have that student explain the answer to the class. Again, the expectation is that everyone is expected to actively participate. An additional complementary strategy to these two strategies is Stretch It (Lemov, 2010). After answering a question, Stretch It is a technique in which the instructor asks additional questions to extend the response, and thus the learning, even further. Such questions as, "How? and "Why?" are repeatedly asked. Are there alternative ways to answer the questions? Are there related skills that can be integrated into the answer? Consequently, as I explained Cold Call and No Opt Out to the workshop participants, I began using Stretch It to extend and deepen the learning.

Ochanji's narrative. On day one of the professional development workshop, I introduced the HRASE questioning strategy. This strategy is utilized for initiating questions at an appropriate level of difficulty and then scaffolding to more challenging questions. It is typically used following a student learning activity. The strategy starts with "safe" questions which are necessary to avoid intimidating students and stifling interaction. The strategy emphasizes students' prior experiences and uses these experiences to build relationships, apply knowledge, and create explanations. This strategy was suggested by Penick et al. (1996) as a questioning strategy particularly suited to science teaching in that it emphasizes students' prior experiences and uses these experiences to build relationships, apply knowledge, and create explanations. HRASE is an acronym for five sequential stages that frame the instructors' questions. These stages are outlined in Figure 1.

\section{HISTORY - QUESTIONS THAT RELATE TO STUDENTS' EXPERIENCE:}

- What did you do ...?

- What happened when you ...?

- What happened next...?

RELATIONSHIPS - QUESTIONS THAT ENGAGE STUDENTS IN COMPARING IDEAS, ACTIVITIES, DATA, ETC.:

- How does this compare to ...?

- What else does this relate to ...?

-What do all these procedures have in common ? 


\section{APPLICATION - QUESTIONS THAT REQUIRE STUDENTS TO USE KNOWLEDGE IN NEW CONTEXTS:}

- How could this idea be used to design . .?

- What recognized safety issues could this solution solve?

- What evidence do we have that supports ?

\section{SPECULATION - QUESTIONS THAT REQUIRE THINKING BEYOND GIVEN INFORMATION:}

-What would happen if you changed ...?

- What might the next appropriate step be

-What potential problems may result from ?

\section{EXPLANATION - QUESTIONS THAT GET AT} UNDERLYING REASONS, PROCESSES, AND MECHANISMS:

- How does that work ?

- How can we account for ... ?

- What justification could be provided for ...?

Figure 1. HRASE Questioning Hierarchy (Penick et al. 1996)

In the professional development workshop, I modeled this strategy through the use of a hands-on science lesson on simple electric circuits in which the instructors participated and I used the strategy to pose questions about the activity.

Masingila's narrative. I chose Scenarios/Case Studies as the strategy I presented on the third day of the workshop. In this strategy, the instructor provides students with a relevant example of a concept, theory, issue, or topic that relates to the day's lesson. Students read the scenario/case study and then discuss and analyze it with a partner or small group. The focus is on applying ideas that the students have learned during the course. If desired, the instructor could have students present their analysis of the scenario/case study to other small groups or record their analysis so the instruction can draw from it for a whole group discussion. If students are familiar with using scenarios/case studies, the instructor could have students develop their own relevant scenarios/case studies and exchange them with other students for discussion and analysis. The scenario/case study I provided the teacher educators with was the following:

Ms. Margaret Wambua is a student teacher on teaching practice. She has learned about using ac- tive learning strategies in her education courses and has experienced her university instructors using these strategies to engage her and her classmates in class. Margaret reports for TP and finds that the secondary students in her classes are not used to being actively engaged in class. In contrast, they are used to simply taking notes that the teacher gives and not participating in class. When she tries to engage the students actively in class, they are silent and do not participate. Margaret believes that her students will learn more if they are actively engaged in the lessons and wants to implement active learning strategies. How should she begin?

I asked the teacher educators to read the scenario/case study, then discuss it with a partner and answer the question. I asked them to be ready to share their answer with others. I chose this strategy because of the potential to use scenarios based on classroom teaching with the opportunity for these teacher educators to engage prospective teachers in reflecting on realistic classroom situations.

Mangram's narrative. I chose Reciprocal Questioning as the strategy I presented on day three of the workshop. Regarding this strategy, the instructor asks the students to generate effective questions about the content materials that they are eventually going to ask of each other. In some instances, the lecture notes can be used to generate the questions. As a group, we discussed the importance of teaching prospective teachers how to identify and ask effective questions. We discussed types of question stems that could be used such as comprehension question stems: What does... mean? Why is...important? How could...be used to...? We discussed connector question stems such as: Explain why...and how...? How are ....and... similar? How are....and...different? How does...tie in with...that we learned before? Again, this technique can be used before, during, or at the end of a lecture.

Since I introduced Reciprocal Questioning on day three of the workshop, I asked the instructors to generate reciprocal questions about the content they learned over the past two days. I then had the instructors turn and ask each other the questions, reciprocating answers and questions back and forth with each other. This strategy motivates the students to think deeply about the information in their notes by asking them to generate germane questions about the information therein. I did ask 
a variety of groups to share their questions and responses. I used Cold Call, No Opt Out and Stretch It to engage the entire group.

\section{WRITING STRATEGIES}

Masingila's narrative. The strategy I chose for the second day was Note Check. When using this strategy, the instructor has each student partner with someone nearby and compare notes, with the focus on summarizing key information and locating any misunderstandings. The instructor could also have students generate a question from this partner discussion or solve a problem posed by the instructor related to the notes. Some instructors might think that using this strategy will be problematic since students may not take notes, but rather rely on their peers to take notes for them. However, this strategy does not involve students giving each other their notes; rather, students are comparing their notes with each other and working together to fill gaps in their collective understanding. Instructors can support students in learning good note-taking skills, as well as gain information about whether or not students are able to identify key ideas in a topic.

To engage the teacher educators in exploring this strategy, I talked about the benefits of actively engaging students in learning and gave some tips for implementation while they took notes. I then asked them to compare their notes with a partner, focusing on summarizing key information and locating misconceptions. I also asked them to generate one question about this topic. This strategy can be implemented in as little as two to three minutes. I chose this strategy because Kenyatta University instructors are heavily reliant on students taking notes, but they may not be using the student notes in the lesson or monitoring what kind of notes students are taking.

Mangram's narrative. The strategy I chose on the second day of the workshop was Focused Listing. In using this strategy, the instructor asks the students to recall what they know about the subject matter by creating a list of the terms or ideas related to it. For example, because I was the first to introduce a new strategy on day two of the workshop, I asked the instructors to list and explain the strengths and weaknesses of all of the active learning strategies we discussed the previous day. This allowed me to check for understanding and notice any trends or thoughts regarding any of the strategies. I then used Cold Call to begin a brief review of yesterday's information while also stretching the concepts where possible. This strategy can be used before, during, or at the end of a lecture. Focused listing can be also used to analyze readings. Two to three minutes are needed to employ this strategy.

Haddix's narrative. The whole-group learning strategies that I selected for the three days each focused on literacy skills in two areas: writing to learn and visual literacy. Writing to learn activities are planned or impromptu informal writing tasks that help students think through key concepts or ideas presented in a class (cf. Readence, Bean \& Baldwin, 2012). Writing to learn activities help students develop a deeper understanding of new concepts introduced, and they allow students an opportunity to make their own connections with the ideas being presented. Given the large lecture-size classes at Kenyatta University, the instructors have little to no control over how students make meaning of the course material. They work to make the information as accessible and engaging as possible with hundreds of students in a class setting. By introducing writing to learn strategies, instructors provide students with tools to be independent thinkers and learners and to best manage their own learning. I wanted to also present strategies where the instructors did not feel that they needed to be completely hands-on in order for the strategy to be effective.

The first strategy I presented on day one was the Two-minute Paper, a writing to learn task. In this strategy, the instructor pauses and asks students to write in response to a question, a statement, or a digital or visual aid presented on a PowerPoint slide. The strategy can be used at any point in a lecture. Prior to beginning a lecture, an instructor might ask students to take two minutes to write about what they have learned from the week's assigned readings, or during the lecture, the instructor might pause and ask students to respond to a quote in two minutes. However, this strategy is particularly useful at the end as a way of encouraging students to summarize the day's content. For example, an instructor might announce, "In the final two minutes of class, write a summary of what you are taking away from today's lecture and what questions you still have." The two-minute paper encourages students to put information in their 
own words, helping them internalize it and identify gaps in their understanding. When collected at the end of the period, the two-minute paper can serve as a classroom assessment technique to help instructors gauge how well students are learning the material, what they understand, and what the instructor needs to spend more time on.

Anticipating that some students may think that two minutes is not a lot of time to write anything significant or they may think that it is too much time and they have nothing to write, I also introduced two additional "writing to learn" strategies that require students to summarize ideas or articulate their points with restrictions. For example, instructors might begin a lecture by asking students to summarize what they already know about a topic in no more than six words. Instructors might also capitalize on students' use of social media by asking students to live tweet in 144 characters during the lecture ideas that resonate with them on Twitter.

The second strategy I presented, on day two, was the Write-Pair-Share (or Think-Pair-Share) strategy. Write-Pair-Share is an active learning strategy that engages students with material on an individual level, in pairs, and finally as a large group. It consists of three steps. First, the instructor poses a prepared question, posts a quote from the reading, or presents a visual or digital aid and asks individuals to write (or think) about it quietly. Second, students pair up with someone sitting near them and read their responses to each other. Third, the instructor chooses a few pairs to briefly summarize their ideas for the benefit of the entire class. When used at the beginning of a lecture, a WritePair-Share strategy can help students organize prior knowledge and brainstorm questions. When used later in the session, the strategy can help students summarize what they are learning, apply it to novel situations, and integrate new information with what they already know. The strategy works well with groups of various sizes and can be completed in as little as two or three minutes, making it an ideal active learning strategy for classes in which lecture is the primary instructional method.

In our professional development workshop, I modeled for the instructors how they might use this strategy during a lecture. First, I asked instructors to view a TED Talk by Nigerian writer Chimamanda Ngozi Adichie titled, "The Danger of a Single Story." Then, on a PowerPoint slide, I presented a quote from the TED Talk followed by a question:

"Now, I loved those American and British books I read. They stirred my imagination. They opened up new worlds for me. But the unintended consequence was that I did not know that people like me could exist in literature. So what the discovery of African writers did for me was this: It saved me from having a single story of what books are." (Adichie, 2009)

\section{WHAT IS THE DANGER OF A SINGLE STORY?}

Spend the next two minutes responding in writing to this question.

I allowed the instructors a few moments to write quietly about the material and then asked them to pair up with someone to share their responses. Finally, I asked a few volunteers to share what they discussed in their pairs. In the end, each group posed new insights and questions for the larger discussion.

On day three, visual literacy was the active learning strategy I shared with the Kenyatta University's instructors. Visual literacy is the ability to interpret, recognize, appreciate, and understand information presented through visible actions, objects, and symbols (Finley, 2014). Visual aids come in many formats. During the workshop, we brainstormed various kinds of visual aids that we use in our teaching. Some examples of visual aids include DVDs, videos, YouTube clips, advertisements, maps, and political cartoons.

I explained that the use of visual literacy complements many of the other strategies presented. For example, the use of a visual aid can be incorporated with the Write-Pair-Share strategy. At any point of a lecture, the instructor can present a visual image on a PowerPoint slide and give the students a few moments to write or think quietly about the image and what meaning they derive from it. Students pair up with a partner and share their written responses. Finally, the instructor can ask for a few group volunteers to share what they discussed.

\section{TECHNOLOGY-SUPPORTED STRATEGIES}

Ochanji's narrative. On day two, the Flipped Classroom was the second strategy I introduced to the instructors. This is an instructional strategy that dedicates more class time to hands-on learning while replacing instructors with supplemental materials such as podcasts, screencasts and videos 
that students can view outside of the class (Bull et al., 2012). The students receive the key instructional elements outside of class. Such instruction can be provided through videos, podcasts, websites, DVDs, CDs, or any other form that provides a clear instructional message. In the classroom, students work together under the guidance of the teacher in applying the instruction to complex problems.

A number of resources have been developed to support this strategy. For example, on its network website (www.flippedlearning.org), the Flipped Learning Network (FLN) has identified four essential pillars of flipped learning abbreviated as FLIP. They include (a) a Flexible environment, (b) a Learning culture, (c) Intentional content, and (d) a Professional educator. These four pillars provide a framework for organizing a flipped learning environment that allows for a variety of learning modes.

In presenting this strategy to the instructors, I wanted them to consider the learning environment by challenging them to consider how they could physically rearrange their learning spaces to accommodate a lesson or unit to support either group work or independent study. I wanted them to create flexible spaces in which students choose when and where they learn and to be flexible in their expectations of student timelines for learning and in their assessments of student learning.

In creating a learning culture, I wanted the instructors to consider ways in which they deliberately shift instruction to a learner-centered approach, where in-class time is dedicated to exploring topics in greater depth and creating rich learning opportunities. As a result, students would be actively involved in knowledge construction as they participate in and evaluate their learning in a manner that is personally meaningful. I also wanted them to consider what content they need to teach and what materials students should explore on their own. The flipped learning content that is made available to students out of class cannot be a direct replica of what the classroom instruction would have been. A lecture presented as a podcast for example could be organized by sub-topics that are about 5-10 minutes long so that student can come back to review it as needed when working on applying that knowledge.

Lastly, I emphasized that the role of a professional educator is even more important, and often more demanding, in a flipped classroom than in a traditional one. While professional educators take on less visibly prominent roles in a flipped classroom, they remain the essential ingredient that enables flipped learning to occur. In the workshop, I tasked the instructors to consider the activities they would use during class time so that they could continually observe their students, providing them with feedback relevant in the moment, and assess their work. As professional educators, they would need to reflect in their practice, connect with each other to improve their instruction, accept constructive criticism, and tolerate controlled chaos in their classrooms.

A number of technology-based resources and strategies exist that allow instructors to instantly check on student learning progress. On day three, I introduced one of these strategies during the active learning training workshop. This strategy was the use of TodaysMeet accessible at www.todaysmeet. com. Designed as a backchannel for the conversation behind what is going on, TodaysMeet creates a personal chat room that the instructor can set up and invite the students.

The students can quickly and easily write comments or questions for anyone in the chat room to see. The instructor creates a virtual meeting room at the beginning of a lecture and makes the website link accessible to the students at the beginning of class. Students use the live stream to make comments or ask questions. The instructor does not need to pose a prompt for the students to respond to; students are free to pose comments or questions that are important to them. The instructor may check the web page during the lecture to see what issues or questions the students have and respond to them or modify instruction to address them. Instructors may use that feedback to tailor the presentation, sharpen the points, and address audience needs in real time (or beyond the lecture). During the professional development workshop, the instructors had the opportunity to practice setting up a TodaysMeet account and a meeting room for one of their classes.

\section{ENGAGING PARTICIPANTS IN USING THE STRATEGIES}

After introducing, modeling and engaging the workshop participants with the new strategies, we each worked with a smaller group of instructors to debrief and discuss the pros and cons of implementing these strategies in our own practice. Our discussion was organized around two items: one, identify some of the roadblocks to implementing each 
strategy in your classes and two, think of examples from one of your own lectures/materials and develop a plan for implementing each strategy.

Before we identified the roadblocks, we highlighted several benefits of actively engaging students in learning with these strategies, including: (a) they facilitate students' conceptual understanding; (b) the instructor is seen as a facilitator of learning, rather than a giver of information; (c) students are generating knowledge, not just receiving information; and (d) the strategies help with integration of information.

While the teacher educators could appreciate the strategies introduced, the number one roadblock was managing large class sizes. Utilizing these strategies increased the possibility of loss of classroom control. For example, when an instructor allows students time to write on their own, there is no guarantee that students are actually using the time to write; additionally it is difficult to regain the students' focus on the actual lecture once you "let them loose" to work on an individual task.

Another idea presented by the Kenyatta University instructors was that they felt the strategies were better suited for use in the primary and secondary schools, where teachers have smaller class sizes. These were strategies that they wanted to teach their prospective teachers to use in their professional practice, but they did not see how they could actually model these strategies within the context of their large lecture classes. This presented a major dilemma-how do teacher educators teach methods without modeling those methods or providing opportunities for student teachers to practice the strategies in their own learning?

The instructors saw great benefit in using the Opening Question/Reflection strategy, as it would get students involved from the beginning of the lesson. They also mentioned that this strategy seemed as if it would be fairly easy for them to integrate into their current lecture method. Because of all the information presented during a lecture, the instructors believed this strategy was an effective means to have the students reflect on past information, as well as speculate about future information without using an inordinate amount of time.

Similarly, the instructors had positive comments about the Cold Call, No Opt Out, and Stretch It strategy. The instructors believed this particular strategy could motivate them to rethink the pre- sentational structure of their lectures, as well as encourage their students to be more active about engaging the material in that particular setting. The instructors did note that it was problematic to call on students in the rear of a lecture hall because the students would not be able to hear each other's comments. Additionally, instructors feared that many students would say "I don't know," or that this technique was better utilized in the seminar sections and not the lecture. Hearing these concerns, we suggested, where possible, for the instructors to move off stage away from the podium and engage the students while also encouraging them to speak up in such a space.

In reflecting upon the HRASE questioning strategy, the instructors identified its focus on science as a limitation. They also pointed out that this strategy was limited to activity-based lessons. However, when challenged to think about other content areas that may involve student hands-on activities, they were able to generalize the use of the HRASE strategy to other subjects such as geography, poetry, music and other broad range of subjects. Again, the challenge of how this strategy could be applied in large classes and the dilemma of not being able to model it to prospective teachers who could easily apply this strategy in their secondary school classrooms, was brought to bear.

While the workshop participants were interested in using Scenarios/Case Studies, they wondered where they would find suitable case studies or scenarios. We discussed that they could develop appropriate examples by drawing on their own teaching experience and experience working with prospective teachers. For example, the instructors could generate case studies around issues such as engaging with parents, teaching controversial or difficult subject matter, having a challenging conversation with a school administrator, or handling a student cheating incident.

Acknowledging that Reciprocal Questioning was an effective strategy, the instructors discussed the different types of question they could ask their students. Further, they discussed how to teach their students to generate and ask effective questions as well as how to do so without disrupting the flow of a lesson. Interestingly, many of the instructors suggested starting with the HRASE model. For instance, the instructors noted that they wanted to teach their prospective teachers to ask students eas- 
ier questions first before asking them more complex questions. The instructors wanted the prospective teachers to use a graduated questioning approach.

Note Check was another strategy that the teacher educators thought they could implement fairly easily. All participants indicated that they currently expect students to take notes, but they do not check these notes in any way. Several teacher educators were quite enthusiastic about using the Note Check strategy to allow students to hold each other accountable for the notes they are taking.

The instructors believed they could immediately implement Focused Listing in their lectures. Realizing that Focused Listing complemented Note Checking and Reciprocal Questioning, the instructors first discussed ways to generate focused listing questions that would motivate their students to strategically review their notes. Next, the instructors proposed having the students create question stems about the notes that they previously reviewed as well as have the students then ask each other questions about this information. The majority of the instructors stated that they would use this strategy at the beginning and end of their classes.

In general, the teacher educators felt it was important to encourage their students' writing practices, and they saw strategies like the Two-minute Paper, Write/Pair/Share, and the incorporation of Visual Literacy as exemplary strategies for doing so. They saw these "writing to learn" strategies as ways to further students' comprehension and application of new topics, and they felt that the use of visual images was critical to teaching large lecturestyle classes. Visual literacy was viewed as a way to enhance the lecture and show illustrative examples of content material. The main reservation was that the teacher educators would not be able to collect written exercises from students to review or provide feedback; they simply did not have enough time or resources. Incorporating these writing strategies was primarily a way to support students' independent learning. The teacher educators questioned whether given the high stakes testing nature of their context if students might expect some form of feedback or formal assessment of their writing, especially since this was not the objective of these strategies.

With regard to the Flipped Learning strategy, the instructors pointed out the lack of resources as an impediment. The alternative media necessary for providing learning material for students to review outside of the class were regarded as either being too expensive, too time consuming, or both. The instructors identified lack of time and lack of technology support necessary to create podcasts, CD ROMS, or DVDs and to upload such material on the learning management system. They, however, noted that these resources could lead to positive returns in the long run since such material may be created once and used several times in subsequent semesters. The concerns regarding resource availability and support are consistent with previous research recommendations on the need to evaluate available resources when considering flipped learning (Bergmann \& Sams, 2012).

Similar technology support challenges were identified for the technology based check-in strategies. Moreover, even though TodaysMeet require students to sign in with a username, it is possible for students to create fictitious names and post abusive notes to the instructor. The limit to the number of words allowable for each post was also seen as a limitation. Most instructors nevertheless saw many benefits of using TodaysMeet. These included using the tool as a record of attendance and a medium for teaching digital citizenry.

\section{CONCLUSION}

Massification does not have to mean a low-quality learning experience despite large class sizes. Indeed, we argue that massification means a different learning experience for instructors and students in Sub-Saharan nations. By using the aforementioned active learning strategies, the lecture method can be transformed into a tool that promotes active rather than passive learning. Because massification is impacting the number of students attending higher education, schools of education must modify how they teach their methods courses in order to model for their pre-service teachers how to actively engage classroom with large numbers of students. This is a significant educational challenge for not only higher education, but also primary and secondary educational institutions that are also facing large class sizes in Sub-Saharan nations.

While these active learning strategies would work well with any size of class, we believe this challenge is an opportunity to rethink the lecture method, to deepen and engage the content in more complex ways, and to move to a more student cen- 
tered approach despite the number of students in the lecture hall.

\section{References}

Badichie, C. N. (2009, July). Chimamanda Ngozi Adichie: The danger of a single story. [Video file]. Retrieved from http:/l www.ted.com/talks/chimamanda_adichie_the_danger_of_a_ single_story?language $=$ en

Bergmann, J., \& Sams, A. (2012). Before you flip, consider this: Leaders of the flipped classroom movement say each teacher will have a different experience, but securing schoolleadership support, time, and IT resources will be important to every effort. (New styles of instruction). Phi Delta Kappan, 94(2), 25.

Biggs, J. (1999). Teaching for quality learning at university: What the student does. Buckingham, UK: Open University Press.

Bloom, D., Canning, D., \& Chan, K. (2005). Higher education and economic development in Africa, Harvard University. Washington, D.C.: World Bank.

Bonwell, C. C., \& Eison, J. A. (1991). Active learning: Creating excitement in the classroom. Washington, D.C.: The George Washington University (ERIC Clearinghouse on Higher Education).

Bull, G., Ferster, B., \& Kjellstrom, W. (2012). Inventing the flipped classroom. Learning \& Leading with Technology, 1, 10-11.

Chrenka, L. (2001). Constructivism and the role of the teacher: Misconstructing constructivism. Phi Delta Kappan, 9, 694695.

Finley, T. (2014). Common core in action: 10 visual literacy strategies. Retrieved from http://www.edutopia.org/blog/ccia10 -visual-literacy-strategies-todd-finley.

Flipped Learning Network (FLN) (2014). The four pillars of F-L-I-

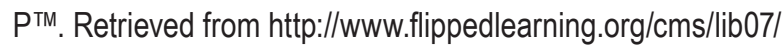
VA01923112/Centricity/Domain/41/FLIP_handout_FNL_Web. pdf.

Houston, J. E. (Ed.) (1995). Thesaurus of ERIC descriptors (13th ed.). Phoenix, AZ: Oryx Press.

Lemov, D. (2010). Teach like a champion: 49 techniques that put students on the path to college. San Francisco: Jossey-Bass.

Mohamedbhai, G. (2008). The effects of massification on higher education in Africa. Report from the Working Group on Higher Education of the Association for the Development of Education in Africa. Retrieved from http://www.2aau.org/ wghe/scm/meetings/mai08/adea/study_massification.pdf.

Mulryan-Kyne, C. (2010). Teaching large classes at college and university level: Challenges and opportunities. Teaching in Higher Education, 15(2), 175-185.

Penick, J. E., Crow, L. W., \& Bonnstetter, R. J. (1996). Questions are the answer: A logical questioning strategy for any topic. Science Teacher, 63, 27-29.

Readence, J., Bean. T., \& Baldwin, R. S. (Eds.) (2012). Content area literacy: An integrated approach (10th edition). Dubuque, IA: Kendall Hunt Publishing.

Scott, P. (1995). The meanings of mass higher education. Buckingham, UK: Open University Press.

Swain, H. (1999, March 12). Intellectuals fight "dumbing down." Times Higher Education Supplement, p. 3.

United Nations Organization for Education, Science and Culture (UNESCO) (1997). Report on the State of Education in Africa: Challenges and Reconstruction. UNESCO Regional Office for Education in Africa (BREDA). Dakar, Senegal: UNESCO.

UNESCO (1999). Higher education and society: A student perspective. Report on the thematic Debate at the World Conference of Higher Education, Paris October 5-9, 1998, Paris: UNESCO.

UNESCO (2007). Education for all. Global Monitoring Report. Paris: UNESCO. 


\section{Author Biographies}

Jeffery A. Mangram is an Associate Professor and coordinator of Social Studies education in the Syracuse University School of Education. His scholarly interests revolve around media education, urban education, teacher education and high leverage practices in the classroom. He also directs the Charles Hayden Summer College Program, in which rising high school seniors of color spend a six-week summer residency program at Syracuse University, where they take college courses for credit. Mangram's work is featured in such publications as Theory and Research in Social Education and the Journal of Social Studies Research. The International Society for Social Studies named Dr. Mangram Outstanding Faculty Member in 2011. He has been a principal or co-principal investigator on approximately $\$ 1.1$ million in grants. He earned his undergraduate degree (Policy Studies/Political Science), master's degree (Social Studies education) and Ph.D. (Teaching and Curriculum) from Syracuse University.

Marcelle Haddix is a Dean's Associate Professor and program director of English education in the Syracuse University School of Education. Her scholarly interests center on the experiences of students of color in literacy and English teaching and teacher education. She also directs the Writing Our Lives project, a program geared toward supporting the writing practices of urban youth within and beyond school contexts. Haddix's work is featured in Research in the Teaching of English, English Education, Linguistics and Education, and Journal of Adolescent and Adult Literacy. Her awards and recognitions include the American Educational Research Association Division K Early Career Award; the National Council for Teachers of English Promising Researcher Award; and the Syracuse University Meredith Teaching Award. She earned a Ph.D. from Boston College, a master's degree in education from Cardinal Stritch University, and a bachelor's degree in English education from Drake University.

Moses K. Ochanji is the Associate Director of the School of Education and an Associate Professor of Science Education at California State Uni- versity San Marcos. He teaches science education and general courses in the teacher credential and the Master of Arts in Education Programs. His research interest focuses on the "multiple phases of inquiry" in science classrooms and issues dealing with science teacher education. He has a wide experience in classroom science teaching having taught high school physics and mathematics in Kenya and in New York State for several years. He was a visiting lecturer on sabbatical leave at the Department of Educational Communication and Technology at Kenyatta University, Kenya, where he taught and collaborated with the department's faculty on research projects focusing on capacity building through quality teacher preparation and issues relating to teaching in large classes.

Joanna Masingila is Dean of the School of Education at Syracuse University, a professor of mathematics and mathematics education, and a Meredith Professor for Teaching Excellence. She has been at Syracuse University since finishing her Ph.D. in mathematics education at Indiana UniversityBloomington in 1992. Prior to her doctoral work, she taught secondary mathematics for six years. Her research interests include teacher development, teacher educator development, mathematical knowledge for teaching teachers, and students' out-of-school mathematics practice. She has been a principal or co-principal investigator on approximately $\$ 5.9$ million in grants, including six from the National Science Foundation and two from the United States Agency for International Development. Masingila has published widely in journals and books, and has developed a number of multimedia case studies examining issues in teaching practice. In 1998, she was a Fulbright Scholar to Kenyatta University in Nairobi, Kenya, and also spent Fall 2011 on research leave there. 